\title{
Visualizing Devices for Configuring Complex Phenomena in-the-Making
}

\author{
Helena Karasti \\ Digital Design Department, IT University of Copenhagen, Denmark/hkar@itu.dk
}

\section{Andrea Botero}

School of Arts, Design and Architecture, Aalto University, Finland

Joanna Saad-Sulonen

Digital Design Department, IT University of Copenhagen, Denmark

\section{Karen S. Baker}

School of Information Sciences, University of Illinois Urbana-Champaign, USA

\begin{abstract}
STS scholars are engaging in collaborative research in order to study extended socio-technical phenomena. This article participates in discussions on methodography and inventive methods by reflecting on visualizations used both internally by a team of researchers and together with study participants. We describe how these devices for generating and transforming data were brought to our ethnographic inquiry into the formation of research infrastructures which we found to involve unwieldy and evolving phenomena. The visualizations are partial renderings of the object of inquiry, crafted and informed by 'configuration' as a method of assemblage that supports ethnographic study of contemporary socio-technical phenomena. We scrutinize our interdisciplinary bringing together of visualizing devices - timelines, collages, and sketches - and position them in the STS methods toolbox for inquiry and invention. These devices are key to investigating and engaging with the dynamics of configuring infrastructures intended to support scientific knowledge production. We conclude by observing how our three kinds of visualizing devices provide flexibility, comprehension and in(ter)ventive opportunities for study of and engagement with complex phenomena in-the-making.
\end{abstract}

Keywords: Visualizing devices, configuration, configuring, visualization practices of arts and design, collaborative ethnography, data generation and transformation, complex phenomena in-the-making 


\section{Introduction}

In this paper we describe, analyze and reflect on how we crafted a variety of visualizations with which we brought together and transformed ethnographic data and insight generated while investigating a complex phenomenon in-the-making. Our use of these devices is framed by an ethnographic interest, but it was also brought forward as an explicit focus on interventive engagement and inventiveness throughout. In doing this, the paper contributes to the discussion on methodography (Greiffenhagen et al., 2011; Lippert and Douglas-Jones, 2019) and inventive methods (Estalella and Criado, 2018; Lury and Wakeford, 2012; Marres et al., 2018).

The phenomenon we studied was the formation of research infrastructures (RI) to support ecological and environmental research. The ecological sciences study biomes with an interest in interactions between organisms and their biophysical environments while the environmental sciences introduce a focus on human influences. Research for these sciences, historically based on data collected at designated locations, consists of two natural science components: biotic (living organisms, such as flora and fauna) and abiotic (physical factors, such as temperature and nitrogen), that reflect the characteristics of each particular biome. Both the idea and the challenge of environmental research infrastructures (ERIs), is to assemble, connect and make comparable heterogeneous data collected at various times and at widely distributed ecological locations. ERIs are intended to bring together data across multiple spatiotemporal scales for collaborative research efforts relating to urgent global problems such as climate change, biodiversity loss, management of natural resources, and sustainability of ecosystems.

The process of forming ERIs, we learned, could hardly be described as being developed through evolutionary trajectories with clear directionality (Pollock and Williams, 2009). Rather their formation appeared only partly materialized and wildly incoherent at times such that their stability and ability to connect could not be assumed (Jensen and Winthereik, 2013). The definition of complexity by Mol and Law (2002) befits ERIs in-formation. They explain, "[T]here is complexity if things relate but don't add up, if events occur but not within the processes of linear time, and if phenomena share a space but cannot be mapped in terms of a single set of three-dimensional coordinates." (Mol and Law, 2002: 1). In our efforts to understand what it takes to form ERIs, we followed their recommendation to pay careful attention to scaling processes, unpredictabilities, multiplicities and emergence. Furthermore, in order to problematize the reductive contrasting of simplicity and complexity (Mol and Law, 2002), we aimed to ask what happens to complexity when simplifications are made.

In our study, one obvious way to contrast simplicity and complexity would be to focus on the tension between simplification and complexity. We encountered simplification in terms of standardization and harmonization instituted by the European Strategy Forum on Research Infrastructures (ESFRI) policy, yet observed researchers coping with the complexity of ecological and environmental sciences, engendered by the diverseness in biomes, sites, temporalities, instruments, methods, units, procedures, practices, etc. resulting in extremely heterogeneous environmental data. We chose to problematize the tension by inquiring into ERI participants' practices with an interest in their practical orientation as they engaged and re-engaged (or not) with RI policy concerns. We also dug into how ESFRI policy - currently the main policy and funding program regulating Rls in the European Research Area - has evolved over the years, as it is also in-formation. With enough understanding of both, we started to speculate about potential alternative encounters and eventually to create explorative opportunities where standardization and complexity could meet care-fully and inventively.

For making sense of ERIs in-formation, we have drawn on Star and colleagues' notion of information infrastructure (Star and Ruhleder, 1996; Star, 1999; Bowker and Star, 1999). This early work puts forth a set of characteristics through which information infrastructures emerge as socio-technically imbricated, relational, (at least partially) invisible, political, and situated - and yet with wide reach. In addition, Karasti and Blomberg (2018) put forward the connected, accreting and emerging qualities 
as well as the variety of intentions and interventions at play in the formation of information infrastructures. From this foundation, we began our study - collaboratively and ethnographically - of a shape-shifting, socio-technically and institutionally diverse and spatio-temporally distributed phenomenon that evolves together with the ways of doing science amidst partnerships, standards, data and policies that are changing over time and affecting how knowledge is produced. We use the term 'ERIs in-formation' for the phenomenon we engaged with in the field together with the study participants and the more ontologically flavored 'complex phenomena in-the-making' for the object of inquiry we researchers created for our investigation.

Given our observations of ERIs in-formation configuring and reconfiguring themselves, we explored ways of looking at and recording some of their different states and shapes through a variety of what we came to call visualizing devices. Some of us were accustomed to drawing and working with pictorials. We began to notice how little-by-little these graphic renderings became an approach that we used frequently. As a result of our own experiences, we also experimented with ways to use them to generate, share and render available what we learned for and with our participants. We used these visualizations as invitations as well as explicit provocations and interventions in the field.

Drawing on methodography (Greiffenhagen et al., 2011; Lippert and Douglas-Jones, 2019), which invites researchers to reflexively examine their own research practices and methods, we frame this paper by asking the following questions:

1) How did we, as researchers, meet and make sense of what we were researching - in this case ERIs in-formation that we characterize as complex phenomena in-the-making - by drawing on Suchman's (2012) configuration?

2) How has our enactment of different visualizations constructed and structured our ethnographic data of the phenomenon? How have they facilitated collaboration in inquiry and in(ter)vention?
In the following section, we introduce the notion of configuration that informs our methodographical reflection, and visualizations from the traditions of arts and design that we mobilized in our research. We then describe our approach to collaborative ethnography. We go on to reflect on how our exploration and wondering about ERI configurations, shaped the generation and transformation of our ethnographic data into a variety of visualizations (timelines, collages and sketches) that rendered visible partial 'cuts' into the object of inquiry and revealed how they were (re)configured as our understanding of the phenomena grew and in(ter)ventive opportunities arose. In the Discussion section, we address our two research questions by deliberating on visualizing devices for making sense of complex phenomena in-themaking in collaborative research. We conclude by positioning visualizing devices in the methods toolbox for scholars interested in use of flexible research designs to study complex phenomena in-the-making.

\section{Configuration and visualization}

Here we introduce our take on Suchman's (2012) notion of configuration, drawing parallels to the ethnographic approach of 'constructing the field'. We then move to the practice of visualizing, which we borrow from art, design, and engineering, as a way of learning about ERIs in-formation and articulating them as complex phenomena in-the-making.

\section{Encountering configuration}

Suchman's (2012) notion of 'configuration' informs and inspires our methodographical reflection. Configuration is a concept for bringing things together into socio-material assemblages for analysis. For us it has two broad uses. First, it aids in delineating what comprises an object of analysis and how it is bound. It provides a vocabulary to understand and question our continuous bounding of the phenomena, drawing parallels to the notion of 'constructing the field' in ethnography (Blomberg and Karasti, 2013). The ethnographic field cannot be taken for granted, as Amit reminds us: 
In a world of infinite interconnections and overlapping contexts, the ethnographic field cannot simply exist, awaiting discovery. It has to be laboriously constructed, prised apart from all the other possibilities for contextualization to which its constituent relationships and connections could also be referred. (Amit, 2000: 6)

Second, the notion of configuration helps draw attention to how imaginaries and materialities are entangled in technologies and their development projects. It supports us in exploring socio-material assemblages as action and effect by directing attention both to the modes of ordering things and to the arrangements of elements in particular combinations. It alerts us to inquiring how things are - over time and through encounters - figured into meaningful existence, "fixing them through reiteration but also always engaged in 'the perpetuity of coming to be' that characterizes the biographies of objects as well as subjects" (Suchman, 2012: 50, citing Daston, 2000). With reference to Law's 'method assemblage' (Law, 2004), configuration can be understood as a device for articulating the relation between what counts as the 'insides' of a socio-technical system and what is considered the 'outsides'. It acknowledges the enacted rather than any given nature of delineations of inside(r)s and outside(r)s. With further relevance to infrastructure development at the core of ERIs in-formation, configuration recognizes the contingency and incompleteness of artifacts, both in terms of a system's description (presupposing 'hinterlands' exist given that full specification of the system is not possible) and its implementation (presupposing design always continues as design-in-use).

In our work, we have enacted configuration both "as a tool to think with about the work of drawing the boundaries that reflexively delineate technological objects, and as a conceptual frame for recovering the heterogeneous relations that technologies fold together" (Suchman, 2012: 48). Configuration underscores the question of differential capacities for the articulation and movement of technological imaginaries and enabling resources, as well as for the complex relationship between the scale(s) of projects and their effects.

\section{Drawing from visualization traditions in the arts and design}

As we have mentioned, and will elaborate in the next sections, visualizations and visualizing practices became one of the biggest 'traces' left by our attempts to understand the phenomena and document our collaboration within the team and with our participants. Thus, in comparison with other methodographical reflections that concentrate on revisiting textual transcriptions (e.g. Greiffenhagen et al., 2011), we take a close look at a set of 'visual designs' in the form of timelines, collages and sketches. These practices are not just the prerogative of the so-called creative professions but are part and parcel of the way science and technology operate (Latour, 1986). Our use of visuals, however, comes with particular customs stemming from design, art, architecture and engineering fields that have long traditions of resorting to a variety of visualizations to render their objects of inquiry and creation (Pollio, 1914; Klee, 1973). For example, in art and design studios, practitioners constantly use different media to explore design alternatives, change viewpoints, make decisions and communicate with different stakeholders (e.g. Retelny and Hinds, 2016). In these traditions, visual and other material representations, including sketches, doodles, technical drawings and 3D models, function as network-organizing devices and receptacles for knowledge that articulate the thought processes of their creators and of those with whom they need to interact (Henderson, 1991, 1998).

Moreover, such pictorials provide not only provide analytical traction (as tools to think with) and interpretative flexibility, they are at the same time purposefully constructed with a variety of interventive and generative intentions. Lynch (1960), for example, developed what he called mental maps of cities based on verbal interviews, sketch maps and field reconnaissance trips in the city, in an effort to better understand cities. Based on the maps, Lynch proposed key elements of the built environment that could be used by urban designers. In this way, the practice reached out to capture people's understanding of "the complexity of the modern city" (Lynch, 1960: 109) and provided generative tools for further design. In the participatory design tradition, the 
creation and use of various visualizations, e.g. 2-D collages and mappings, 3-D mockups, storyboards, diaries, game boards, props, etc., as tools for collaborative design is widespread (e.g. Brandt et al., 2013) and inclusive of joint thinking and drawing both with other participants as well as with the materials themselves (Henderson, 1991; Latour, 2008; Schoffelen, 2015). The 'making' gives the participants pause to reflect, learn and teach one another as they move development towards making joint decisions (e.g. Botero Cabrera et al., 2008; Donovan and Baker, 2011; Baker, 2017) or while articulating issues of mutual care and concern (Lindström and Ståhl, 2014; Schoffelen et al., 2015). Because of the pragmatic orientation of many pictorials and visual models in design, it is also important to note how they often ignore, omit and delete details and relations that allow the designers to move on (Agid and Akama, 2018), despite running the risk of presenting things as 'fixed'.

\section{Collaborative ethnography of ERIs in-formation}

In this section we outline aspects of our collaborative research approach with a flexible study design that enabled our explorations with visualizing devices.

\section{Our team and research practices}

Our interdisciplinary team consisted of five researchers from different backgrounds, including environmental sciences, engineering, design, social sciences and STS. We, the four authors of this paper, had varied levels of experience in ethnographic and interventive research approaches as well as in studying ERIs. We created joint workspaces on university servers and used file sharing services to support our collaborative sessions, both face-to-face and virtual, which were instrumental for the ongoing sharing, analyses, and decision-making about constructing the field, delineating our object of inquiry, and strategizing about our research design.

With regard to data generation, our approach was inclusive; we were open to all methods that seemed applicable. While participant observation and interviews, in various forms, were an integral part of our fieldwork, we also generated data through other methods, such as perusing our own and the study participants' archives when they were shared with us, returning to old surveys, and organizing a workshop with our study participants including conducting surveys with workshop participants before and after the event. Desk ethnography played an important part in following ethnographic cues and leads, such as names, acronyms, places, diagrams, events or Rls mentioned in interviews and documents. Our multi-modal data came to be made up of field notes, audio and video recordings and their transcripts, websites (documents from past ones and links to contemporary ones), a vast variety of documents and artifacts, survey data/responses as well as photographs and video clips. Over time, we collected an increasing number of scribbles, diagrams and sketches drawn on paper as well as in digital formats created by us and by our study participants. We juggled and juxtaposed these visualizations as part of the processes of data generation, constructing the field, delineating the object of inquiry and as a way to understand ERI configurations. We produced an assortment of visualizations for and during our joint analyses and discussions, and also for a number of purposes beyond our team, including as interventions at events we organized.

We were acutely aware that many of our study participants were practitioners tangling with the challenging realization of the ERI(s) in-formation. Therefore, we tried to make available our own tentative insights along the way in the hope they would be useful for them, thus extending collaborative activities beyond our team. Furthermore, we were interested in the possibilities to engage with participants in critical, yet also caring and creative interactions that might intervene in the phenomena, and allow for inventing together (Marres et al., 2018), thereby aligning also with an ethical orientation of 'standing with', rather than solely 'giving back' (TallBear, 2014).

\section{The unfolding process of studying ERIs in-formation}

We initially set out to study the Finnish Long Term Socio-Ecological Research Network (FinLTSER), whose first decade had been characterized by 
funding uncertainty, false starts and dead ends. We soon started to question our focus starting with our first visit to one of the FinLTSER sites as we learned that a subset of FinLTSER member sites had reorganized to become a 'research stations' component in a new consortium for upgrading and coordinating ERIs nationally, an effort called INAR RI Ecosystems (see Table 1 with some key actors and their acronyms for our study). The study participants pulled us into their lives including their interests and anticipations with new ERI developments.

Tracing the leads we were gathering, we sought to understand transitions taking place in the national ERI landscape. In addition to people from the FinLTSER Network and the new INAR RI Ecosystems Consortium, we interviewed several stakeholder groups involved in RI policy making. The ERI in-formation was embedded nationally both in the transitioning field of environmental research and in the RI policy landscape actively in development. While collaboratively mapping out this ERI in-formation, we became convinced that we should extend our ethnographic field again. Tight connections were apparent with the European LTER Network (Müller et al., 2010; Singh et al., 2013), where preparations for submitting a RI proposal, called eLTER RI, to the European ESFRI Roadmap were ongoing. This was of obvious interest to FinLTSER/INAR RI Ecosystems Consortium since getting accepted as part of the larger European ESFRI Roadmap would promote a place in Finland's national RI roadmap (FIRI) and thus funding, making the ERI more viable in Finland.

\section{Crafting visualizing devices for ERIs in-formation}

In this section we reflect on the visualizations we have crafted while generating and transforming our ethnographic data. We describe three kinds of visualizing devices: timelines, collages, and sketches, examples of which are presented below. We recount our initial intentions and the processes of crafting the visuals together with our reflections on the curiosity, wonder, readjustment and creative care experienced in relation to the ever-changing events, alignments, uncertainties, ambiguities, frictions and surprises provided to us by the ERIs in-formation that we studied and with which we engaged.

\section{Devising timelines for looking backwards and considering intertwined processes}

In the beginning we wanted to share the first author's knowledge of FinLTSER within our team because Helena had investigated and participated in the FinLTSER network between 2006 and 2014 through previous research efforts. As a way of starting work in our current research project, Joanna interviewed Helena over a period of two days. During planning for the interview, the idea of using a timeline surfaced. While timelines are widely used for scheduling, budgeting and project management in organizations (Yakura, 2002), we were inspired by Bowker's musings on the need for mapping the temporalities of an infrastructure and that some kind of visualization tool would help show the shape and nature of an infra-

Table 1. List of abbreviations and definitions of institutional entities that are a mix of consortia, networks, research infrastructures and policy programs.

\begin{tabular}{|l|l|}
\hline Acronym & Unabbreviated definition \\
\hline eLTER RI & $\begin{array}{l}\text { Integrated European Long-Term Ecosystem, Critical Zone \& Socio-Ecological Research } \\
\text { Infrastructure, a RI proposed by LTER-Europe Network and accepted on ESFRI Roadmap in } \\
2018\end{array}$ \\
\hline ESFRI & $\begin{array}{l}\text { European Strategy Forum on Research Infrastructures, the strategic initiative formed in } \\
2002 \text { to make policy and fund RIs for European Research Area }\end{array}$ \\
\hline FinLTSER & Finnish Long-Term Socio-Ecological Research Network, established in 2006 \\
\hline FIRI & $\begin{array}{l}\text { Finnish Research Infrastructure, the national RI policy and roadmap of Finland, FIRI } \\
\text { Committee established in 2012 }\end{array}$ \\
\hline INAR RI Ecosystems & $\begin{array}{l}\text { INAR RI Ecosystems Research Infrastructure Consortium, a project funded for 2017-2021 to } \\
\text { develop ecosystem RI capacity in Finland }\end{array}$ \\
\hline LTER-Europe & Long-Term Ecosystem Research Network in Europe, launched in 2003 \\
\hline
\end{tabular}




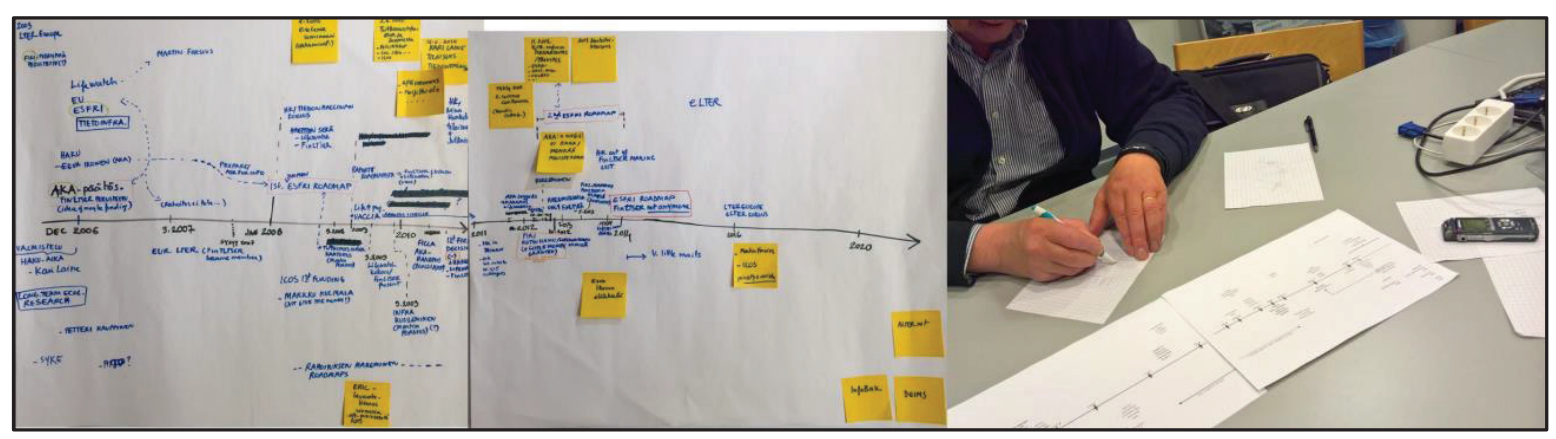

Figure 1. The first version of a timeline hand-drawn during Helena's interview (left) and a cleaned up, digitized version used with another interviewee (right).

structure at different moments (Bowker, 2015). We also drew from our previous work on collaborative mapping to visualize complex settings (Botero Cabrera et al., 2008; Baker, 2017; Bødker et al., 2017).

During the interview, Helena reflected back on the formation of the FinLTSER, prompted by questions and the timeline that Joanna was drawing on a big sheet of paper (Figure 1, left) as well as by digging into her own computer archives of emails and documents. Helena later said that she felt constrained at times by having to think chronologically during these sessions, while Joanna, in turn, was eagerly trying to pin down information on the timeline. Joanna found herself overwhelmed by the amount of information as well as the multitude of acronyms being used. However, working together on the timeline provided a shared point of reference which we updated continuously with input from our subsequent study participants. Grappling together with the dates, key actors, organizations, events and milestones was one way to construct an initial, shared understanding of the "rocky road of FinLTSER", as Helena called it. Discussing the retrospective interview and the resultant timeline with the other members of our team allowed for a 'fast backwards' look. This prompted initial discussion and reflection on what FinLTSER was and how we understood ERIs and their formation.

We used a streamlined version of the timeline in ensuing interviews with key FinLTSER participants as a tool to think together and to help the interviewees recall past events (Figure 1, right). In some cases, it was clear that the timelines were useful for the study participants. Some suggested amendments, bringing in their own history and understanding of certain aspects or facets of what we were trying to map. Others asked us if they could keep a copy of the printed timeline, because they thought it might be useful for their own work. The timelines became concrete devices to invite our study participants to join in our quest. In other cases, some interviewees simply glanced at them and we were left wondering whether it was worth the effort to edit and print the timelines.

We crafted the timelines when preparing for and carrying out interviews, and then during debriefing afterwards. While editing the timelines, Joanna also resorted to desk research, sometimes creating links to online documents for the digital versions of the timeline. She saved each version with its own name, so that each timeline was preserved and could be checked at any time. For her, the timelines offered a sense of grounding in the project and helped her get past the uncertainty associated with trying to navigate unknown territories. The timelines became a kind of map to keep in one's pocket for easy reference when facing new information or analyzing existing data such as the interview transcripts. Later, when Andrea joined the project, she also used the timelines to help catch up with the rest of the team and get an overall understanding of the phenomenon being studied and of the data available.

The initial FinLTSER timeline was focused in its visualization on the unfolding of only one research network, with scattered indications of key moments and events that were related in some way or another to FinLTSER. Prompted by interviewees, we added other events to the FinLTSER trajectory, mostly denoting national and international RI policy and funding activities. We included 
additional LTER related developments such as major transformations occurring in approaches to environmental research in Finland and Europe. When we later brought the timeline to interviews with INAR RI Ecosystems Consortium participants, we added other national and European ERI formations as study participants shared their experiential knowledge of them, thereby helping us understand how relations with these entities were unfolding.

As the visualization kept expanding, along with our perspectives, we started seeing more clearly how the 'rocky road' trajectory of the FinLTSER was embedded within a multitude of related processes taking place simultaneously. Our work on subsequent renderings of the timelines allowed us to better understand and bring forward, in a visual form, the intricate webs of relations and interdependencies reaching across national and European arenas, exemplified by the RI roadmap processes with which the ERIs need to align.

Almost three years after making the first timeline, we decided to produce reworked versions of the timeline(s), to use for wider dissemination. We wanted to more clearly separate into different layers the various chronological events identified by our participants. Figure 2 shows how we added dynamic elements (arrows), in an attempt to move beyond the rigidity of the chronological delineation and make visible relations between events. We also removed some events and simplified dates and side interactions depicted in other versions of the timelines. The aim was to communicate how the European and national road map processes impacted the 'rhythm' of various developments. The interrelations between European processes relating to policy and funding seemed to multiply and were in turn influenced by and interacted with increasingly dense national developments.

The many parallels depicted in the timelines, reminded us of the steep learning curves associated with collaborative research efforts, RI development, and RI policy making that the many actors were experiencing while facing pressures from various directions. It suddenly didn't appear so surprising anymore that FinLTSER had early on experienced difficulties getting funded. While working on the timeline compilation, with the benefit of our retrospective point of view, Helena wondered whether having had earlier such an overview of all the intertwined processes, would have alleviated FinLTSER participants' frustrations while they were trying to establish continuity for FinLTSER.

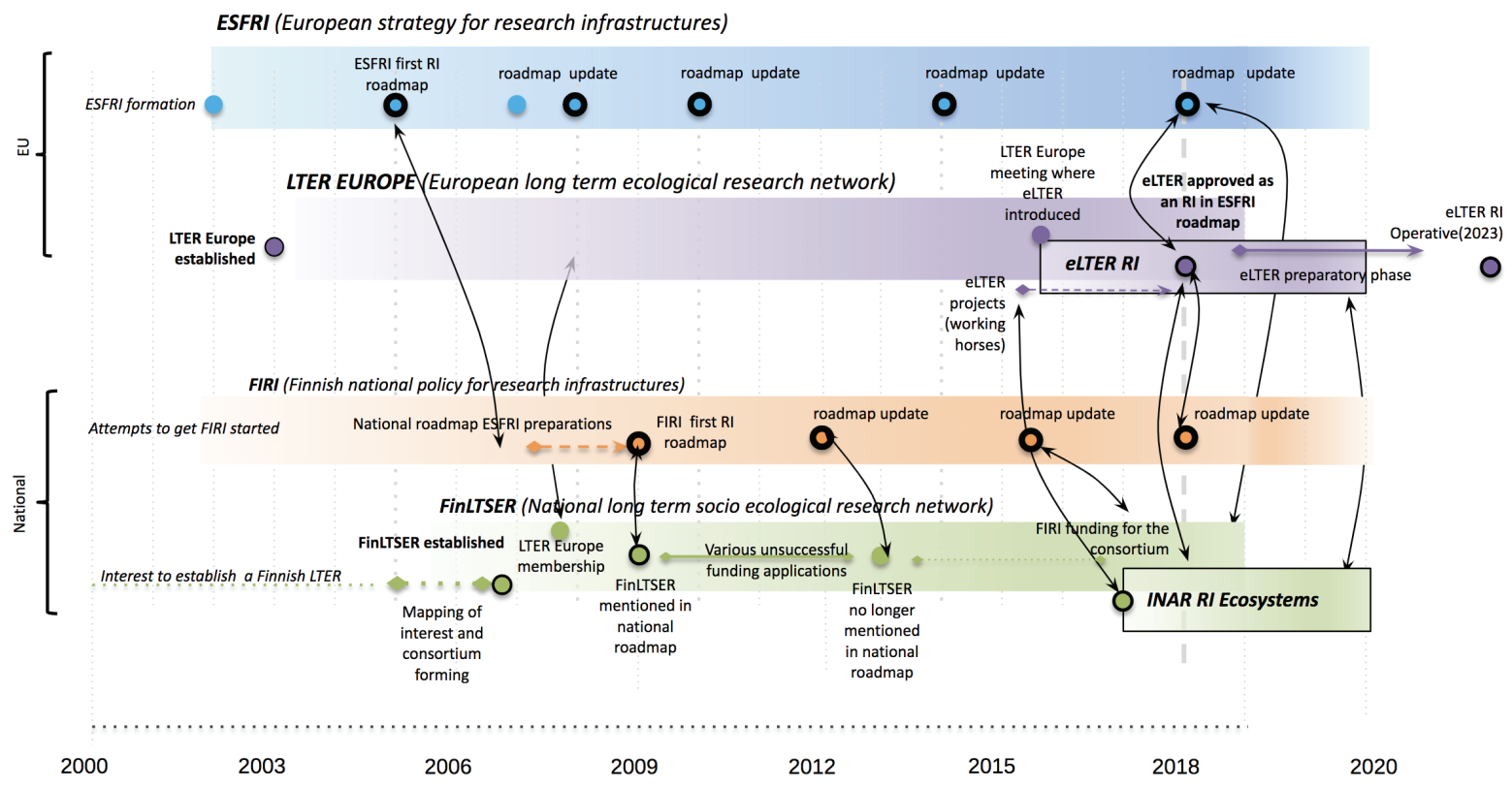

Figure 2. One of the reworked versions of a timeline, showing some milestones and interrelations of ERIs in-formation such as the dots that highlight roadmap activities. Redrawn from hand drawn and annotated timelines constructed within the team and with our study participants. 
These visualizations made it possible (perhaps too easily) to depict the European ESFRI as a layer 'overseeing' all the developments (at the top of Figure 2) and the European LTER-Europe (shown immediately below the ESFRI layer) morphing gradually into an emerging eLTER RI. The timelines pinned these developments down, but they certainly lacked granularity in other important dimensions that are not bound to events, e.g. becoming an international entity; making a community; inquiring about key moments rather than missed opportunities.

The timelines have been our constant companions in our own quest - offering different kinds of support to each of us - and have also provided a much-needed concrete artifact to think with as a team as well as together with our study participants. The timelines as we have drawn them, however, also caused frustration because the chronological dimension dominated, making it difficult to incorporate related threads and other dimensions. Furthermore, as with Helena's initial reaction to the first timeline, such devices often force us to pin things down, thereby hindering us from attempting more flexible and fluid visualizations.

\section{Collaging to relate and juxtapose for pursuing and speculating (dis)connects}

During our fieldwork, we learned that ESFRI became essentially the only policy and funding opportunity available for creating pan-European domain-specific RIs (Papon, 2004; Gübitz et al., 2012). Consequently, the ESFRI Roadmap - one of the key mechanisms of the hierarchical regulatory approach of ESFRI policy - became an obligatory passage point to which several of our study participants devoted much attention. To understand this relationship, we found it useful to work with some visualizations.

We started looking closely at visualizations created by some of our participants. We came across many graphical representations that focused on the local context. For example, the more established 'installed base' of FinLTSER made up of the research stations, often would have a photo of their biome type as well as a description of their physical facilities and instrumentation. FinLTSER Network, in turn, had a map and descriptions of the member sites, while INAR RI Ecosystems Consortium did not have any diagrams as their organization was so recent. In addition, visualizations were often created with manage-

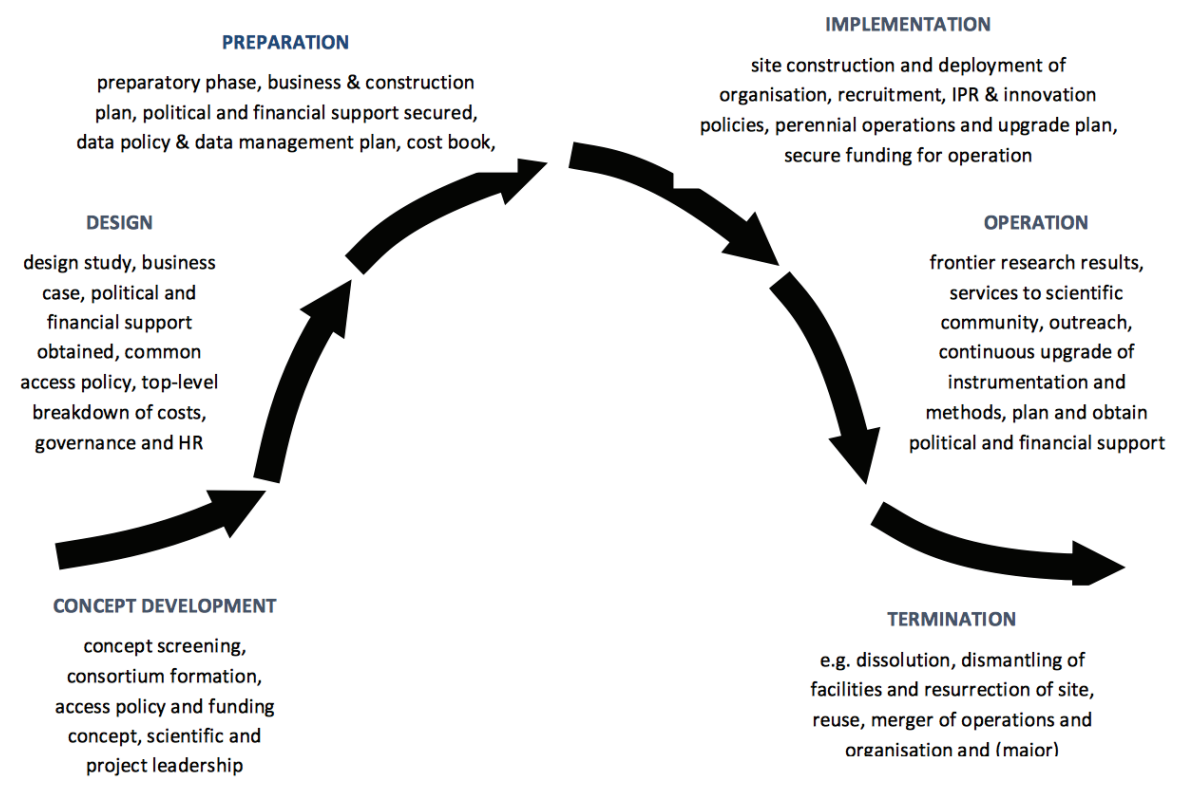

Figure 3. ESFRI's rendering of the lifecycle model to follow for the development of all RIs in Europe. The diagram is taken from the ESFRI manual for applicants to the 2018 roadmap (ESFRI, 2016:11) and does not label the $x$ or $y$ axes. We assumed the $x$-axis represents time, and the $y$-axis resources, as that is the general depiction used in project life cycle management models (see e.g. Carayannis et al., 2005). 
rial interest and/or by those participating in the $\mathrm{RI}$ policy-related activities, such as proposal preparations. These figures, tables and illustrations - quite understandably - were steered by and oriented towards the ESFRI policy. From the point of view of ERI(s) in-formation, they depicted a variety of aspects relating to "how to become a RI". In order to be recognized as an ESFRI RI and obtain funding for construction, ERIs in-formation need to be first approved for the ESFRI Roadmap. ESFRI follows a 'lifecycle model' for the development of all RIs accepted to its Roadmap (ESFRI, 2016). The ESFRI documents depicted this lifecycle with an abstract and orderly diagram (see Figure 3 ) in the form of a six-stage arc depicting the stages of a RI from 'concept development' to 'termination' (ESFRI, 2016: 11). Such an orderly depiction of an RI process, however, did not capture the dynamics we were seeing in the field with ERIs in-formation.

During our analytic and speculative discussions, we took some RI development diagrams we had collected and, based on them, created a variety of collages to explore relations associated with ERIs. Doing this brought ESFRI policy models as well as the large-scale ERIs and their extended formation processes together. We found ourselves annotating them, highlighting what was missing, asking questions prompted by them, and trying to identify the hidden assumptions that undergirded them. We made annotations and juxtapositions in a free association mode (as an artist will do). We were often frustrated by the impossibility of accommodating all the details and possible comparisons in the collages. Decisions had to be made about what to include and what to exclude.

Through making sketches and building collages, we started articulating a variety of tensions between the top-down, standardizing, and unifying aspects of the ESFRI Roadmap and the heterogeneous technoscientific practices of environmental field research. Would the ERI(s) in-formation aim to be inclusive of ecology's tradition of small science, including heterogeneities in study objects, instruments, methods, categories, typologies, etc. (Borgman, 2015; Bowker, 2000), that result in extremely heterogeneous ecological data (Karasti and Baker, 2004, 2008)? How would the different national ERI formation

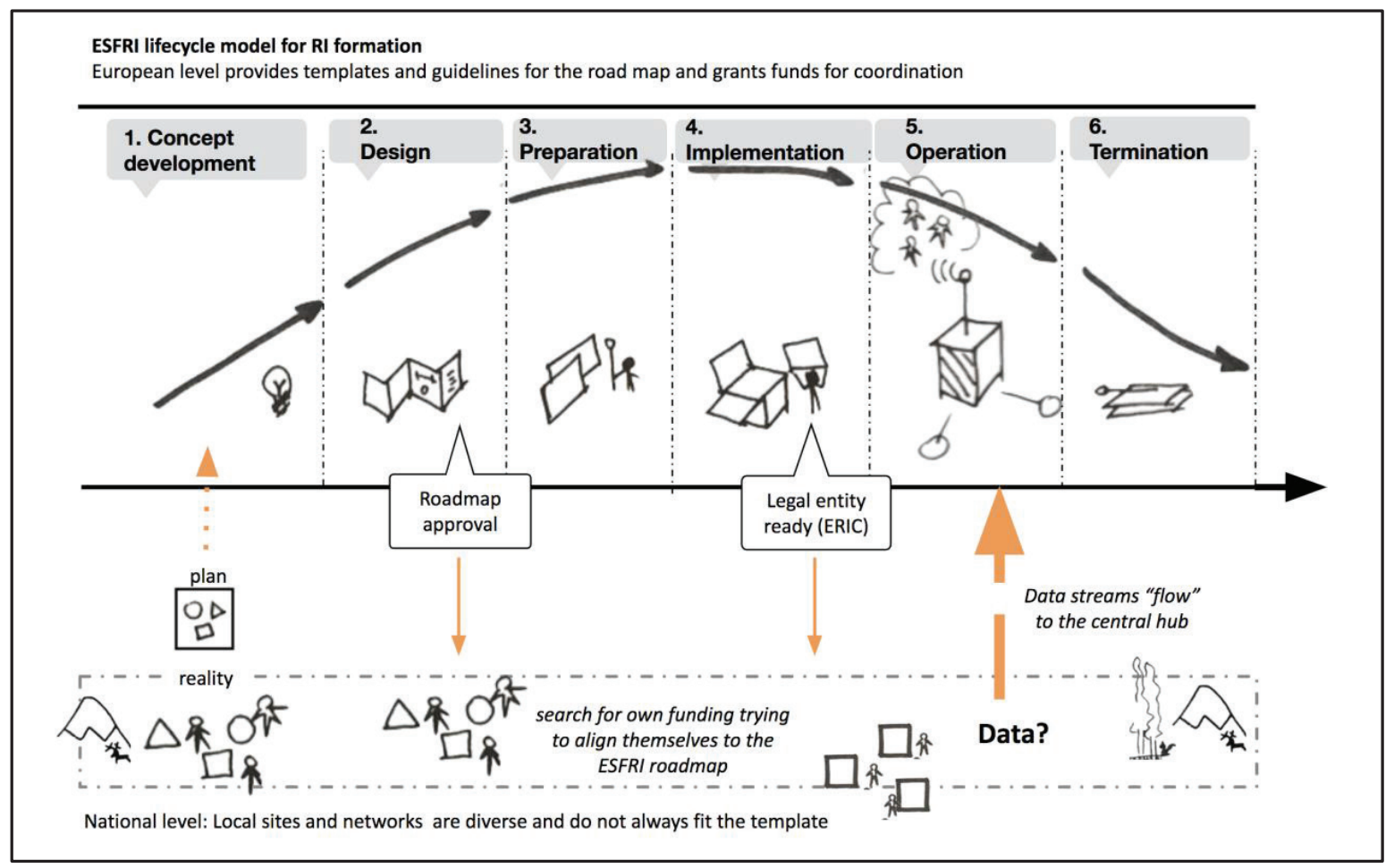

Figure 4. This collage depicts in the upper panel a version of the lifecycle model created by us for constructing RIs according to ESFRI. The lower panel, in parallel, depicts the national and/or local activities of member networks of the European LTER Network. These local/national actors are supposed to obtain national RI funding in order to provide 'good quality data' to the planned eLTER RI during its phase of operation. 
processes be aligned with ESFRI's 'one size fits all' development model?

To help us think about the eLTER RI formation process, we reused the ESFRI lifecycle model for constructing RIs (Figure 3 ) and augmented it (Figure 4, top panel) with drawing annotations and 'little people' doing things and with our own evolving view of a layer depicting the RI formation processes of the national member networks (Figure 4, bottom panel). In the ESFRI process, the local and national RIs become recognized when the need for data to flow into the central hub of the RI becomes imminent at the operational stage of the life cycle. This is a level-spanning activity, depicted in the Figure 4 collage by a thick upward arrow linking the bottom and top panels. The flow of data between layers indicates an assumption (made by the ESFRI model), an expectation that data management procedures are in place at national and local levels such that they are able to produce good quality data for the pan-European RI. However, despite the crucial role local ecological/environmental data gathering and data management play in ERIs, activities in the lower part of the figure that we added to the collage have been overlooked and/or underappreciated in the original 'top-heavy' ESFRI model. Existing local and national data management and infrastructure efforts often, as exemplified by Finland (Karasti, 2009), are very heterogeneous and distributed and, as yet, frequently lacking in coordination both with local LTER sites and across them. They are 'bottom-heavy' enterprises.

In bringing the two panels together in Figure 4, we wanted to create a provocative juxtapositioning. By making visible the gap between the European and national spheres and by allocating the few connections expected to 'happen' in certain phases, we were thinking out loud: How could they connect? How to create in-between processes? We have used different versions of this figure in various interventions, including workshops at conferences (Baker et al., 2018; Botero et al., 2019), a field guide to ERI formation (Botero et al., in preparation) and other dissemination outputs (Parmiggiani et al., 2019; Botero et al., 2019). We also used this collage in kicking off a workshop we organized for the INAR RI Ecosystems Consortium that is described in the following section.

\section{Sketching the conceptual, the existing, and the imagined}

The data management workshop we organized with and for the INAR RI Ecosystems Consortium brought together research station staff and associated researchers. For the Consortium, the workshop was a contribution to their capacity building activities related to data management. For us, it was an opportunity to interact further with Consortium members, provide them insights into our ongoing research as well as continue our inquiry (Karasti et al., 2018a).

We planned the workshop with the idea of building bridges to the larger ERI landscape that confronted INAR RI Ecosystems Consortium members. As many of the participants were unfamiliar with both ESFRI and eLTER RI, our aim was to heighten their awareness of the increasing influence of ESFRI policy in steering the formation of both the eLTER RI and national RIs. We decided to start by contextualizing some of the data issues of European Rls by presenting Figure 4. We hoped it would seed discussion on how the policy might manifest in their future data management practices. In response to the figure, there was some consternation regarding the expectations for local and national data management as well as about the need to connect up with the ongoing formation of eLTER RI. Some participants even joked about the 'gap' between the European and national spheres being "as wide as the Grand Canyon". Conversely for some of the participants familiar with ESFRI and eLTER RI who were already fluent with navigating across the extended geographical, organizational and institutional aspects of LTER-Europe, this gap was not easy to recognize.

We wanted to move - collaboratively - beyond the dichotomic 'top-down' and 'bottom-up' stances often depicted. Consequently, we repurposed Karen's earlier definition and conceptual sketch (Baker, 2017; Millerand and Baker, 2020) of a 'data landscape'. This offered us a way to introduce some basic ideas about data management in the ecological and environmental sciences as well as about how data management could create needed bridges. Figure 5 was to present the data landscape notion by depicting three flexible categories as a continuum: a circle on the left 
standing for 'field' where data is collected, a cloud in the middle depicting the 'local' where data are collectively managed and stored, and a square on the right called 'remote' where aggregated data are archived. The sketch was meant to encourage participants to think and discuss about their own data management work (or lack thereof) using this simple, shared conceptual schema. And, indeed, the participants at the workshop talked about data landscape components and their relations, disconnects and arrangements involved in creating Rls, often realizing that there was more involved than they had anticipated in doing 'data management'.

Towards the end of the workshop, we invited participants to sketch with felt pens on large paper sheets their own data activities and arrangements using some of the concepts in the sketch (Figure 5) as a starting point. Our intention was to encourage generation of a collection of participants' heterogeneous data practices and to probe the diversity that existed. For the second part of the sketching exercise, we asked participants to extend their drawing to include other systems, interactions and the connections they imagined could be part of their near future, considering also options they had learned about from the workshop presentations.

The data landscape sketch in Figure 6 was drawn by a research station participant. It shows not only her local data management arrangements but also the connections within the landscape. On the left, the drawing details 'random data' as distinct from long-term instrument stations' data. It lays out how data collected in the field is sent to a local data repository. The repository is labeled as a university database project where an approaching meteor signals the uncertainty of its short-term funding. The right side depicts how data from this database had already been provided to DEIMS (the Dynamic Ecological Information Management System supporting LTER-Europe's site information repository). In addition, the sketch reveals some ways in which its creator was imagining being in a position to send data to a number of other remote, large-scale data facilities in the future.

We asked participants to share their sketches for collective review. During the exchange, we heard data-centric accounts of a wide range of practices, specimens, products, technical systems and fragmented arrangements at the different sites. Participants began to realize there were many potential ways that things could be 'connected up'. The absence of a single 'right' or 'permanent' solution was often an unexpected realization. This spurred a number of participants (like the author of Figure 6) to begin thinking innovatively and strategically about the connections they might choose to make in creating their place in the data

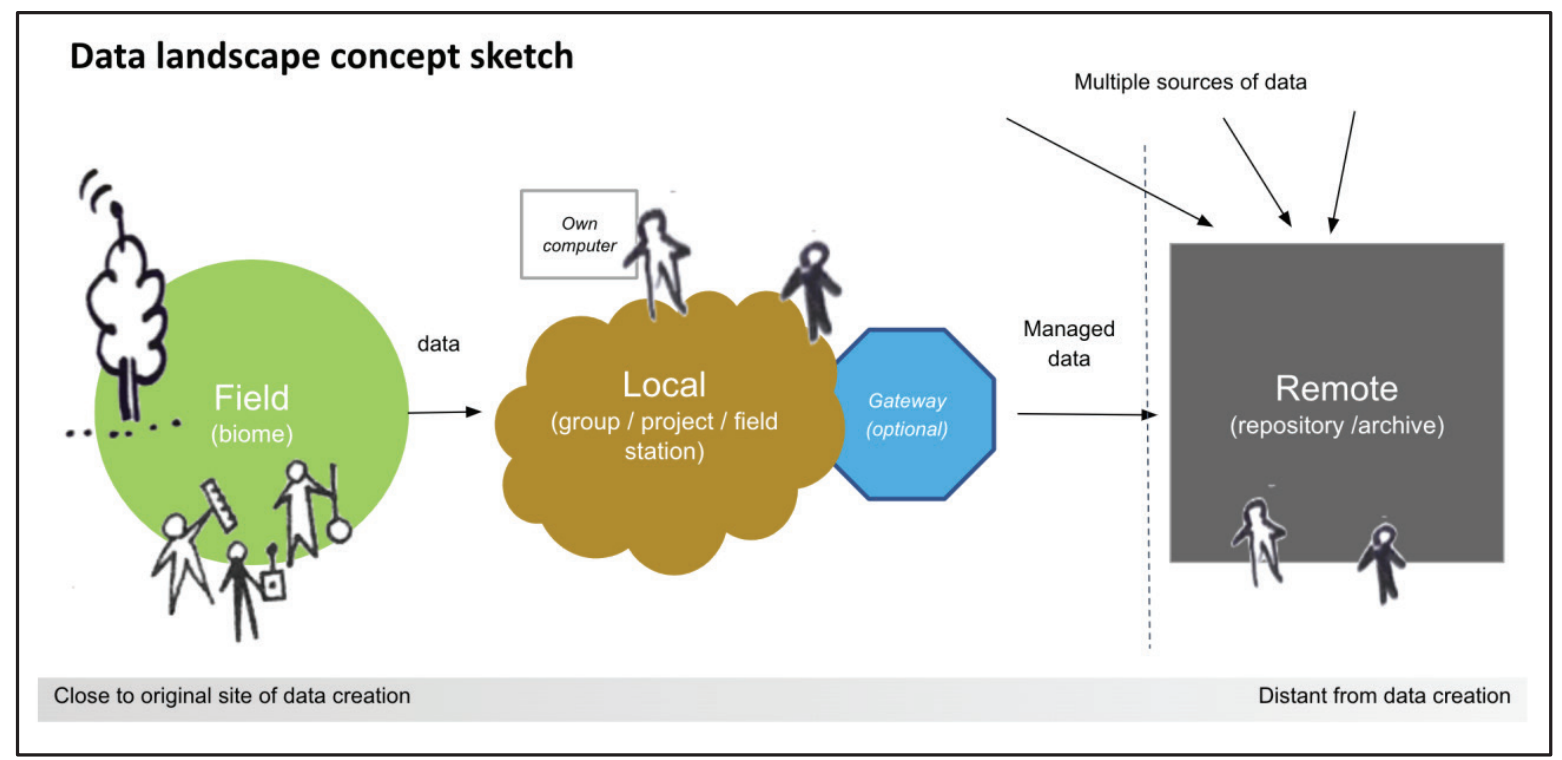

Figure 5. A conceptual sketch with three categories - field, local, remote - introduces the notion of data landscape. This is a slightly simplified version of the one shown and explained during the workshop. 


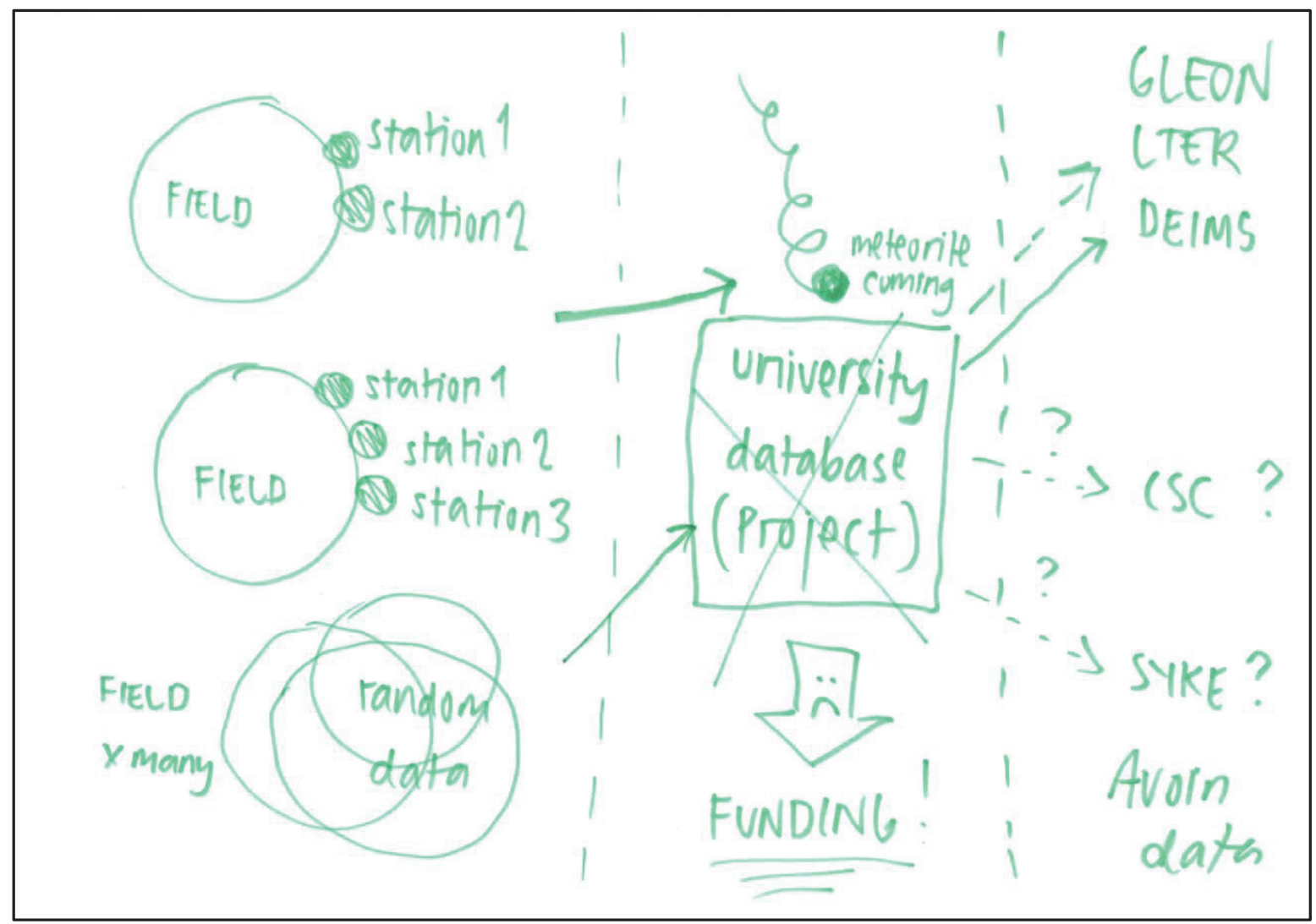

Figure 6. A sketch drawn by one of the research station participants in response to our invitation to present their station's current (solid arrows) and imagined (dashed arrows) data arrangements. Note, the word 'station' in the sketch refers to the research station's several instrument installations in the field. The sketch uses some of the conventions of the field-local-remote continuum we introduced (see Figure 5).

landscape. The exercise allowed some participants to create a variety of 'connected' data landscapes by imagining how to bridge the gap in Figure 4 and for others it made more visible existing disconnects. Overall, it seemed that data concerns had been growing in participants' minds though rarely articulated, and rarely in the presence of others having similar concerns.

We found it a major challenge to create conditions for 'mutual learning' (Simonsen and Robertson, 2013) about data management in ERIs. The concepts were so foreign to many of the workshop participants that we worked at 'taming' them by streamlining and presenting them as simplified definitions relating both to the participants' particular situations as well as the distant world of ERIs. Our designing of materials required many iterations, first to develop and clarify our own ideas and then to consider how to develop a simple and flexible, yet also conceptually sound, guide for participant sketches. We aimed to foster an attitude toward the changing data landscape as not only obscure, abstract, and remote ("on the other side of the gaping gap") but also as inclusive of everyday, familiar, and ongoing. We wanted to avoid staying with the dichotomic interpretation of the two sides separated by a gap (Figure 4), i.e. the upper panel denoting the standardization-bound Rl policy poised to iron out the heterogeneities in the lower panel depicting LTER sites and national networks. Instead, we framed the question of connecting up by thinking about embracing the two sides of the gap into a data landscape (as shown in Figure 5). With this approach participants were able to position themselves wherever they saw fit, to be at liberty to sketch their own data landscapes (e.g. Figure 6). These sketches constituted a varied collection of local and sometimes expanded data management arrangements that fostered collaborative learning, reflection, and ideation in and around the complex ERIs in-formation. 


\section{Reflections on the visualizing devices}

Our three devices - timelines, collages, and sketches - became links to different but related aspects of the RIs. We drew the timelines, by ourselves and with our study participants, in attempts at making sense of a chronology of events and situations. The timelines (Figures 1 and 2) accumulated and juxtaposed mainly administrative, management, and policy information that was generated starting with our initial interviews about previous or ongoing efforts. As we initiated discussions with study participants, work on the timelines facilitated communications. It served as more than a historical chronology, where missing entries would prompt memories of related happenings and illustrate their interconnectedness. Timelines brought together accounts as participants built upon existing versions. As these devices were developed, they accompanied us to subsequent conversations, thereby providing exposure to previously unrecognized aspects of ERIs in-formation in addition to reiterating certain themes at the expense of others.

With collaging, we took study participants' diagrams, which in ethnography are typically used for the purposes of analysis, and continued annotating them and reworking them into diagrams of our own. This helped us question assumptions, inquire about unrepresented elements while inviting imagination, and to bring forward our own insight as researchers. Our collages (Figure 4) started as a simplified timeline of the proposed multi-year development and use trajectories of the ongoing ERI efforts. As we discussed the participants' diagrams, our own sketches allowed us to assemble elements and to create a 'multiview' visualization. Having made research station visits and attended LTER network meetings, we juxtaposed these different views to make visible and emphasize the role of these infrastructuring efforts vis-a-vis a process defined from the top-down. Indeed, we carefully included tiny people, documents, and instruments in our visuals as reminders of the liveliness and the intricateness being visualized.

Finally, sketches, created for and during the data workshop, highlighted data management embedded within the larger data landscape of ERIs in-formation. We designed a three-panel template (Figure 5) to guide participants in thinking about the data they gathered and that which passed through their hands. Our workshop aimed to raise participant awareness about the many choices that arise in the handling and creating of paths for the movement or flow of data (Leonelli, 2020). We emphasized that considering how the data was moved from the field to its destinations would present them with a variety of opportunities. Indeed, visualizing devices allowed us to prompt participants grappling with notions of data management and research infrastructure to consider depicting in their own sketches (Figure 6) both existing as well as potential ways of configuring their ERIs in-formation.

Visualizations were brought into our research collaboration by members of our team with a more design-oriented background. We found working with these devises was useful in dealing with the unruly phenomena we were investigating. We recognize that we might not have turned to visuals in the same way, had we been working together in the same office, or had each one of us been doing fieldwork alone. Deprived of many visual clues, body language, and a common physical site when working at-a-distance, it was helpful to have a shared object for pointing, annotating and drawing. As our collaborative analyses were more relations-oriented and associative than close readings of transcribed data, shared objects helped in keeping focus but also in thinking broadly in meaningful ways. Visualizing devices were useful both for our exploration of the phenomena and befitting our circumstances.

\section{Discussion}

In our study of the making of RIs that aim to support scientific knowledge production in ecological and environmental research, visualizing devices proved invaluable in capturing for display and discussion the multiple aspects of data, projects, networks and policy landscapes. The composing of visualizing devices was directly related to the generation, analyzing and transformation of our ethnographic data. It was through working with the visualizations that we were able to articulate our findings and mull over the complexities and emergence involved in our object of 
inquiry. In the following, we first weigh in on how we, as researchers, have met and made sense of the complex phenomena in-the-making that we were researching. We then move to a discussion of how our enactment of the different visualizations constructed and structured our ethnographic data while facilitating collaboration in inquiry and in(ter)vention.

\section{Making sense of complex phenomena in-the-making via 'configuring'}

In working with and reflecting on the visualizing devices, it has been helpful to distinguish between the ERIs in-formation as something we engaged with in the field, the ethnographic field as constructed, and the object of inquiry as delineated. The difference between them is to some extent analytic; for the researcher they are all ongoing and intertwined during an investigation. The work of crafting visualizing devices moves between these empirical-analytic ways while paying attention to what is being investigated, hence the devices are positioned in relation to the phenomena, the constructed ethnographic field, and the delineated object of inquiry.

Informed by Suchman's configuration as an aid for delineating the composition of an object of inquiry (Suchman, 2012), visualizing devices are crafted to bring together, relate and bound 'things' (elements of the studied phenomena) into assemblages, which is particularly helpful when things did not always add up in ERIs in-formation (Mol and Law, 2002). The researcher, in the process of pursuing the phenomenon, follows relations and connections, identifies disconnects while continuously making decisions about what to include and what to leave out. Bounding the field and the object of inquiry in relation to the phenomenon is the active reflexive accomplishment of the researcher. At the same time, the visualizing devices allow us to explore (with) different framings of the object of inquiry as suggested by Winthereik et al. (2002), where each of the pictorials produced with visualizing devices is a rendering of an experimentation with a different, partial way of constituting the object of inquiry. In fact, some of the potential of visualizing devices resides in the researchers' skill and vision to bring together and establish relations with(in) data, materials and visualizations in varied ways for different purposes. The process introduces a specific accountability to the phenomenon. This is not a straightforward task, accomplished in a single movement but rather an ongoing activity closely related to constructing the field and delineating the object of inquiry. In this way, visualizing devices stay tuned to the 'happening' of the sociomaterial world, "its ongoingness, relationality, contingency..." (Lury and Wakeford, 2012: 2).

Each of our visualizing devices opened a particular 'cut' into our object of inquiry, as they attend to the impossibility of mapping ERIs in-formation once and for all on a single set of coordinates (Mol and Law, 2002). Taken together, as a collection, they nonetheless offer a partial take on the object, glimpses of the many complex configurations that all those involved (us included) were attempting to grasp and convey. Even if there were many more of these devices, they would still not necessarily create a comprehensive, let alone complete picture of the complex phenomena. A strategy of multiplication of visualizing devices could never 'add up' to a whole, nor would they necessarily create an exhaustive or unified picture of the object of inquiry. As Strathern explains, the problem is that the more attempts are made to fill in empirical or analytical 'gaps', the more other gaps become visible, as "the perception and filling of a gap lead to awareness of the 'gaps'"' (Strathern, 1989: 63).

As we followed Suchman's configuration (2012) by attending to the materialities of ERIs in-formation and exploring their existing imaginaries as well as creating possibilities for alternative inventiveness, we became increasingly aware of how continuity and change were constantly intertwining within the processes of 'becoming a Rl'. The ERIs were (based on) already existing research networks, thus they were both transforming their installed bases and simultaneously becoming something entirely new. Our study participants were actively balancing the intricate (non)-existence of FinLTSER, due to its unfunded yet formally recognized status and its partial merging into INAR RI Ecosystems Consortium at the time of our study. An equally convoluted reconciliation was taking place with the ongoing morphing occurring alongside co-existence with the long- 
lived LTER-Europe and the planned eLTER RI. The ERIs in-formation required, from all of us and our devices, some degree of flexibility, attentiveness and responsiveness to the phenomena in-themaking as well as an appreciation of their evolving and emerging nature.

With regard to Suchman's notion of configuration, our suggestion relates in particular to heightened attention to the pervasiveness of (re)configuring and thus consideration of temporality. Although the temporal dimension is definitely manifold and something that should be explored further, at this point for us it relates largely to 'unfolding', 'emerging' and 'becoming'. These temporalities were apparent in our visualizing devices: timelines both reaching to the past where installed bases have started to accrue, recognizing 'the historical anteriority' (Suchman, 2012) as well as expanding to multiple different temporalities of parallel unfolding processes; collages showing the actual emerging processes in relation to the planned RI formation lifecycles; and sketches of data landscapes providing a temporal movement forward from the existing via dashed lines that identify potential future connections marking likely spaces for change. Together the examples draw attention to the continuity of change, to the multi-dimensional emergence, and to "the perpetuity of coming to be" (Daston, 2000: 1). Exploring these visualizations as 'visualizing devices', we focus on and lift up the use of 'configuring' to capture the processual, to highlight the continuing emergence of phenomena in-the-making, similar to the movement from 'infrastructure' to emphasize 'infrastructuring' as an active process (Star and Bowker, 2002; Karasti and Syrjänen, 2004; Karasti and Baker, 2004; Karasti, 2014; Karasti et al., 2018b). The ontology of 'emergence' or 'becoming', we suggest, is crucial for alternative ways of engagement with the formation of technologies and infrastructures.

With visualizing devices, we were able to bring attention to the emergence of ERIs in-formation, as iterations of snapshots. As snapshots, our visualizing devices were not meant to be final or 'ready', not when they were first created, nor throughout their iterations. In reviewing our use of visualizing devices, we see how they have a sketchy aspect, akin to the ways low fidelity proto- types are discussed by design professionals (Rudd et al., 1996; Erickson, 1995), where the unfinished nature of these prototypes allows for discussion and further modification (Schoffelen et al., 2015). Since visualizing devices typically evolve with each iteration as nuance is added to the understanding of the phenomenon, they routinely result in a series of visualizations. By following the continuous construction of the field and enabling emergence of new collaborations (Estalella and Criado, 2018), these series become traces that record the research and thought processes of those engaged in thinking together and who are collaboratively exploring complex phenomena in-the-making. They are only useful insofar as they are read as snapshots that 'freeze' particular configurings (Agid and Akama, 2018).

\section{Enacting visualizing devices in collabora- tive research}

Suchman reminded us that configuration is "both a method through which things are made, and a resource for their analysis and unmaking or remaking" (Suchman, 2012: 49). For us that means that crafting a visualizing device, reflexively, can be an analytic accomplishment 'capturing what is' but it can also be experimental, exploratory and even generative. It appears as an invitation 'inspiring what might be'. Visualizing devices provide a means to bring into relation chosen aspects of the studied phenomenon, e.g. connection, juxtaposition, alignment, comparison, resonance, tension, and disconnect. Thus, the devices may bring together - even momentarily as the phenomenon is evolving - a variety of views of the configurings(s). Because devices can also be created with a variety of inquiring and in(ter)ventive intentions, they provide opportunities for thinking and making together, thus adding strong participative possibilities (Estalella and Criado, 2018). Enactments with visualizations are acts of configuring.

For example, the different 'cuts' present in the devices could be composed in ways that research interest(s) of those involved are incorporated in varied ways, or framed (visually) to productively render surprise(s) to the researcher (Winthereik et al., 2002), or arranged to reveal a troubling circumstance. Their collective enactment can 
also remind or nudge study participants to consider collectively issues of concern, or care (Lindström and Ståhl, 2014). Moreover, by allowing visualizing devices to be collaboratively shaped and reshaped, it is possible to trigger exchange between researchers and participants, and between participants themselves. On such occasions, they can also "invite, persuade or (to put it more strongly) provoke actors and situations to generate accounts, and to produce expressions and articulations of social reality" (Marres et al., 2018: 28, italics original).

The three visualizing devices presented above illustrate these possibilities. The temporal or chronological composition of the timelines allows for analysis and exploration of the past trajectory of the rocky road of FinLTSER on the RI roadmaps. The juxtaposing composition in the collage contrasts the generic, highly structured, and planned European ESFRI lifecycle vis-a-vis the unfolding and unexplored national RI formation processes, thereby creating an in-between space to make a critical point about power imbalances (Star, 1999; Baker and Karasti, 2018). However, the gap also marks a space potentially fruitful for anticipation, imagination and invention. The sketches in turn illustrate how alignment with a conceptual schema can seed both articulation and generative thinking starting from everyday data arrangements at research stations and creating spaces for imagination of environmental data management in the era of Rls. The visualizations bring together heterogeneous details - from heterogeneous sources - to explore, or play with different takes on the complexities of the ERIs in-formation. With our own simplifying visualizations of ERIs in-formation, all of us involved could reflect about what happens to complexities in general when simplifications are made (Mol and Law, 2002). Enactments with visualizing devices contribute to understandings of and opportunities for configuring complex phenomena in-themaking.

Visualizing devices benefit from visual language conventions, notations and principles used in art and design traditions, but they have less ambitious visual goals. Just as sketches and drawings can provide analytical traction and interpretative flexibility to creative practitioners
(Retelny and Hinds, 2016; Henderson, 1991), visualizing devices provide both researchers and participants with material elements to think with and make decisions about their object of inquiry as they compose the devices and understand possible new configurations (Lindström and Ståhl, 2014; Schoffelen et al., 2015). In doing so, they help in understanding 'insides' and 'outsides' of socio-technical systems (Law, 2004). Researchers thus have an active and reflexive role in identifying options. They make decisions about inclusion and exclusion, about how to draw the relations while bounding the arrangements by creating visualizing devices, and about how to craft invitations for imagination and invention into them. The active role of researchers in creating and eliciting visualizing devices sets these devices apart from other materials and other devices that are collected from the study participants themselves for analysis and scrutiny by the ethnographer. In our case they are the outcome of the relational invention (Estalella and Criado, 2018) we constructed collaboratively.

\section{Conclusion}

In this paper we have described and analyzed our practices with visualizing devices that became our constant companions in our engagement with the studied phenomenon, across a range of our purposes, for inquiring, intervening and inventing. We have started a methodographical account of how we have generated and transformed data in our research collaboration by using visualizing devices that capture some of the elements and dynamics associated with complex phenomena in-the-making: the temporal unfolding and relating of multiple processes (timelines), the bringing into relation multiple viewpoints (collages), and the communication across multiple positions and diverse participants (sketches). These visualizing devices were key to working collaboratively both within our interdisciplinary team as well as in interacting, making sense, and imagining together with participants.

The visualizing devices afforded the creation of a series of 'cuts' of the phenomenon - in a manner similar to how the more standardized conventions of plans, sections, and elevations would for 
a building or a terrain. However, for configuring complex phenomena in-the-making, the 'cuts' need to be reflexively created to account for the phenomena investigated, the ethnographic field constructed, and the object of inquiry informed by research interests. In answering Suchman's invitation to think of how to bound a phenomenon and Law's call to consider inclusion and exclusion, we reflect on how we are engaging in, but also critically questioning, simplification by creating presences and absences, and even Otherness. We learned it is important to approach our devices not as fixed but rather to insist on their openness for further revising and re-shaping (see also Callon, 2002). Visualizing devices can help researchers and participants 1) to orient with openness and curiosity towards the studied phenomena, 2) to continuously (re)organize observations in relation to the studied phenomena, and 3 ) to gain more understanding of how researchers and/or participants are configuring complex phenomena in-the-making. Therefore, it is important to keep in mind that visualizing devices are methods in-themaking as are the phenomena their crafters investigate.

Ruppert et al. (2013: 36) have recently pointed out that "[T] he re-emergence of visualization as key to social analysis is striking". They identify the contemporary need for social science methods to handle quantities of data from digital devices and highlight the power of digital visualization to reduce "excessive' information" to a more meaningful form. Our own work shows how other types of (non-digital) data and intentions also benefit from translation via visualization. Unlike the examples from Ruppert et al., we used hand drawn pictorials for making visible and making sense of the messy details as well as the potential configurations of infrastructure. When crafting pictorials, various iterations were needed to attain visual artifacts that made some of the "patterns, circulation, flows, and boundary maintenance and leakage" (Ruppert et al., 2013: 36) more graspable, but also are illustrative of the agency of those creating the visualizations. These iterations required continuous analysis and discus- sion together with study participants, in order to negotiate similarities, differences, and incommensurabilities. Although with roots in design, we see this work akin to the recent discussions in social science around inventive methods (Lury and Wakeford, 2012), the need to engage with the invention of the social (Marres et al., 2018), and to be well aligned with collaborative understandings of ethnography as an inventive practice (Estalella and Criado, 2018).

And last, we already know that methods are performative (Law, 2004) as are research designs (Hyysalo et al., 2019). ERIs in-formation, like any other phenomena researchers address with sensitivity to both complexity and continuous becoming, call for research designs that are geared towards concern for heterogeneities and responsiveness to ongoing change. Consequently, there is a need for method devices that are both agile and flexible enough to be able to deal with configuring, multiplicities, openendedness, unpredictabilities, and emergence as well as with relations across multiple boundaries. Such devices include capabilities to trace and keep in focus a large assembly of sites, disciplines, institutional hierarchies, centers, hinterlands, and nations as both digital capacity and policy push Rls towards 'connecting up'. Configuring includes (re)alignments that alter the landscape in which environmental knowledge production takes place. We discovered visualizing devices were a way to gather together and work with some of the changing circumstances as well as the diverse insights we encountered; a way of thinking together and with participants in order to consider the shape and ever-changing configurations associated with ERIs in-formation. While simply doing and/or adding visualizations is not enough, in(ter)ventions with visualizing devices that are co-created in the field can create interesting openings for those involved. Our experiences suggest that iteration, circulation and constant questioning with visualizing devices unleashes the potential for both configuring and collaborative insights. 


\section{Acknowledgements}

Our warm thanks go to the study participants including FinLTSER and INAR RI Ecosystems in particular. We acknowledge our earlier team member Elena Parmiggiani and extend thanks to the editors and reviewers of this special issue. We acknowledge the Multics project support by the Academy of Finland grant \#285903. Andrea acknowledges the support of the Academy of Finland grant \#34374270. 


\section{References}

Agid S and Akama Y (2018) Dance of designing: Rethinking position, relation and movement in service design. ServDes 2018 Proceedings. Milan, Italy, 18-20 June 2018: 800-811. Milan, Italy: POLIMI.

Amit V (ed) (2000) Constructing the Field: Ethnographic Fieldwork in the Contemporary World. London: Routledge.

Baker KS (2017) Data Work Configurations in the Field-Based Natural Sciences: Mesoscale Infrastructures, Project Collectives, and Data Gateways. PhD Thesis, University of Illinois Urbana-Champaign, United States. Available at: https://www.ideals.illinois.edu/handle/2142/98131 (accessed 18.11.2020).

Baker KS, Botero A, Geirbo HC, Karasti H, Marttila S and Saad-Sulonen J (2018) What does infrastructuring look like in STS? When? Workshop Report. In: EASST Review 37(4). Available at: https://easst.net/article/whatdoes-infrastructuring-look-like-in-sts-when-workshop-report/ (accessed 18.11.2020).

Baker KS and Karasti H (2018) Data care and its politics: Designing for a neglected thing. In: Huybrechts L, Teli M, Light A et al. (eds) 15th Participatory Design Conference Proceedings Hasselt and Genk, Belgium, 20-24 August 2018: 1-10. New York, USA: ACM.

Blomberg J and Karasti H (2013) Reflections on 25 years of ethnography in CSCW. Computer Supported Cooperative Work (CSCW) 22: 373-423.

Borgman CL (2015) Big Data, Little Data, No Data: Scholarship in the Networked World. Cambridge, MA: MIT Press.

Botero Cabrera A, Naukkarinen A and Saad-Sulonen J (2008) Mapping Social Practices through Collaborative Exercises and Visualizations. In: 5th Nordic Conference on Human-Computer Interaction: Building bridges Proceedings, Lund, Sweden October, 2008: 419-422. New York, USA: ACM.

Botero A, Baker KS and Karasti H (in preparation) Field Guide to Environmental Research Infrastructures.

Botero A, Karasti H, Saad-Sulonen J et al. (2019) Drawing Together: Infrastructuring and Politics for Participatory Design - a Visual Collection of Cases, Issues, Questions, and Relevant Literature. University of Oulu. Available at: http://urn.fi/urn:isbn:9789526222042 (accessed 18.11.2020).

Bowker GC (2000) Biodiversity Datadiversity. Social Studies of Science 30(5): 643-683.

Bowker GC (2015) Temporality, the infrastructure toolbox, theorizing the contemporary. Fieldsights 24. Available at: https://culanth.org/fieldsights/temporality (accessed 18.11.2020).

Bowker GC and Star SL (1999) Sorting Things Out: Classification and Its Consequences. Cambridge, MA: MIT Press.

Bødker S, Lyle P and Saad-Sulonen J (2017) Untangling the Mess of Technological Artefacts: Investigating Community Artefact Ecologies. In 8th International Conference on Communities and Technologies Proceedings, Troyes, France, June 26-30 2017: 246-255. New York, USA: ACM.

Brandt W, Binder T and Sanders EB-N (2013) Tools and Techniques: Ways to Engage Telling, Making, and Enacting. In: Simonsen J and Robertson T (eds) Routledge International Handbook of Participatory Design. New York, NY: Routledge, pp.145-181.

Callon M (2002) Writing and (re)writing devices as tools for managing complexity. In: Law J and Mol A (eds) Science and Cultural Theory. Durham, NC: Duke University Press, pp.191-217.

Carayannis EG, Kwak Y-H and Anbari FT (2005) The Story of Managing Projects: An Interdisciplinary Approach. Westport, CT: Greenwood Publishing Group.

Daston LJ (2000) Biographies of Scientific Objects. Chicago, IL: University of Chicago Press. 
Donovan JM and Baker KS (2011) The Shape of Information Management: Fostering Collaboration Across Data, Science, and Technology in a Design Studio. Scripps Institution of Oceanography Technical Report, June 2011. Available at: http://escholarship.org/uc/item/42s1q6mt (accessed 18.11.2020).

Estalella A and Criado TS (eds) (2018) Experimental Collaborations: Ethnography through Fieldwork Devices. New York: Berghahn.

Erickson T (1995) Notes on Design Practice: Stories and Prototypes as Catalysts for Communication. In: Carroll JM (ed) Scenario-Based Design: Envisioning Work and Technology in System Development. New York, NY: John Wiley \& Sons, pp. 37-58.

ESFRI (2016) Public Roadmap 2018 Guide. European Strategy Forum on Research Infrastructures. Available at: http://www.esfri.eu/sites/default/files/docs/ESFRI_Roadmap_2018_public_guide_f.pdf (accessed 18.11.2020).

Greiffenhagen C, Mair M and Sharrock W (2011) From methodology to methodography: A study of qualitative and quantitative reasoning in practice. Methodological Innovations Online 6(3): 93-107.

Gübitz T, Janssen J and Renner C (2012) Development of Research Infrastructures in Europe. Bonn, Germany: ERA-Instruments. Available at: https://www.dfg.de/download/pdf/foerderung/programme/wgi/era_ instruments_paper_part_iii.pdf (accessed 18.11.2020).

Henderson K (1991) Flexible sketches and inflexible data bases: Visual communication, conscription devices, and boundary objects in design engineering. Science, Technology \& Human Values 16(4): 448-473.

Henderson K (1998) The role of material objects in the design process: A comparison of two design cultures and how they contend with automation. Science, Technology \& Human Values 23(2): 139-174.

Hyysalo S, Pollock N and Williams R (2019) Method matters in the social study of technology: Investigating the biographies of artifacts and practices. Science \& Technology Studies 32(3):2-25.

Jensen CB and Winthereik BR (2013) Monitoring Movements in Development Aid: Recursive Partnerships and Infrastructures. Cambridge, USA: MIT Press.

Karasti H (2009) FinLTSER Network formation and the state of information management. Ecological Circuits - Eco-informatics in Action 2: 15-18.

Karasti H (2014) Infrastructuring in Participatory Design. In: 13th Participatory Design Conference Proceedings, Research Papers - Volume 1, Windhoek, Namibia, 6-10 October 2014: 141-150. New York, USA: ACM.

Karasti $\mathrm{H}$ and Baker KS (2004) Infrastructuring for the long-term: Ecological information management. In: 37th Annual Hawaii International Conference on System Sciences Proceedings, Big Island, HI, 5-8 January 2004. IEEE.

Karasti $\mathrm{H}$ and Baker KS (2008) Digital data practices and the Long Term Ecological Research Program growing global. International Journal of Digital Curation 3(2): 42-58.

Karasti $\mathrm{H}$ and Blomberg J (2018) Studying infrastructuring ethnographically. Computer Supported Cooperative Work (CSCW) 27(2): 233-265.

Karasti $\mathrm{H}$ and Syrjänen A-L (2004) Artful infrastructuring in two cases of community PD. In: Clement A, de Cindio F, Oostveen A-M, Schuler D and van den Besselaar P (eds) 8th Conference on Participatory Design Proceedings, Volume 1,Toronto, Canada, 27-31 July 2004: 20-30. New York: ACM Press.

Karasti H, Botero A, Baker KS and Parmiggiani E (2018a) Little Data, Big Data, No Data? Data Management in the Era of Research Infrastructures, Workshop Report. Hyytiälä Forestry Field Station, Finland, 26-27 April 2018. Available at: http://urn.fi/urn:isbn:9789526220062 (accessed 18.11.2020).

Karasti H, Pipek V and Bowker GC (2018b) An afterword to 'Infrastructuring and Collaborative Design'. Computer Supported Cooperative Work (CSCW) 27(2):267-289.

Klee P (1973) Pedagogical Sketchbook. London: Faber and Faber. 
Latour B (1986) Visualisation and cognition: Drawing things together. Jai Press 6: 19-68.

Latour B (2008) What is the Style of Matters of Concern? Amsterdam: Van Gorcum.

Law J (2004) After Method: Mess in Social Science Research. London: Routledge.

Leonelli S and Tempini N (eds) (2020) Data Journeys in the Sciences. Cham: Springer Open.

Lindström K and Ståhl Å (2014) Patchworking Publics-in-the-Making: Design, Media and Public Engagement. PhD Thesis, Malmö University, Sweden.

Lippert I and Douglas-Jones R (2019) Doing data: Methodography in and of STS. EASST Review 38(1): 35-39.

Lury C and Wakeford N (2012) Inventive Methods: The Happening of the Social. London: Routledge.

Lynch K (1960) The Image of the City. Cambridge, MA: The MIT Press.

Marres N, Guggenheim M and Wilkie A (eds) (2018) Inventing the Social. Manchester, UK: Mattering Press.

Millerand F and Baker KS (2020) Data infrastructures in ecology: An infrastructure studies perspective. In: Oxford Research Encyclopedia of Environmental Science. Oxford: Oxford University Press. Available at: http:// hdl.handle.net/2142/109229 (accessed 28.01.2021).

Mol A and Law J (2002) Complexities: An introduction. In: Law J and Mol A (eds) Science and Cultural Theory. Durham, NC: Duke University Press, pp.1-22.

Müller F, Baessler C, Schubert H and Klotz S (eds) (2010) Long-Term Ecological Research: Between Theory and Application. Dordrecht: Springer.

Papon P (2004) European scientific cooperation and research infrastructures: Past tendencies and future prospects. Minerva 42(1): 61-76.

Parmiggiani E, Karasti H, Baker KS and Botero A (2018) Politics in environmental research infrastructure formation: When top-down policy-making meets bottom-up fragmentation. Platypus. Available at: http:// blog.castac.org/2018/06/research-infrastructure/ (accessed 18.11.2020).

Pollio V (1914) Vitruvius: The Ten Books on Architecture. Cambridge, MA: Harvard University Press.

Pollock N and Williams R (2009) Software and Organisations: The Biography of the Enterprise Wide System or How SAP Conquered the World. London: Routledge.

Retelny D and Hinds P (2016) Embedding intentions in drawings: How architects craft and curate drawings to achieve their goals. In: 19th ACM Conference on Computer-Supported Cooperative Work and Social Computing Proceedings, San Francisco, CA, 27 Feb-02 Mar 2016: 1310-1322. New York: ACM Press.

Rudd J, Stern K and Isense S (1996) Low vs. high fidelity prototyping debate. Interactions January 1996:76-85.

Ruppert E, Law J and Savage M (2013) Reassembling social science methods: The challenge of digital devices. Theory, Culture \& Society 30(4): 22-46.

Schoffelen J, Claes S, Huybrechts L, Martens S, Chua A, and Moere AV (2015) Visualising things. Perspectives on how to make things public through visualization. CoDesign 11(3-4): 1-14.

Singh SJ, Haberl H, Chertow M, Mirtl M and Schmid M (eds) (2013) Long Term Socio-Ecological Research: Studies in Society-Nature Interactions Across Spatial and Temporal Scales. Dordrecht: Springer.

Simonsen J and Robertson T (eds) (2013) Routledge International Handbook of Participatory Design. New York: Routledge.

Star SL (1999) The ethnography of infrastructure. American Behavioral Scientist 43(3): 377-391.

Star SL and Bowker GC (2002) How to infrastructure? In: Lievrouw LA and Livingstone SL (eds) The Handbook of New Media. Social Shaping and Consequences of ICTs. London: Sage, pp.151-162.

Star SL and Ruhleder K (1996) Steps toward an ecology of infrastructure: Design and access for large information spaces. Information Systems Research 7(1): 111-134. 
Strathern M (1989) Between a melanesianist and a deconstructive feminist. Australian Feminist Studies 4(10): 49-69.

Suchman L (2012) Configuration. In: Lury C and Wakeford N (eds) Inventive Methods: The Happening of the Social. London: Routledge, pp.48-60.

TallBear K (2014) Standing with and speaking as faith: A feminist indigenous approach to inquiry [Research note]. Journal of Research Practice 10(2): Article N17.

Winthereik BR, de Bont A and Berg M (2002) Accessing the world of doctors and their computers: 'Making available' objects of study and the research site through ethnographic engagement. Scandinavian Journal of Information Systems 14(2): 47-58.

Yakura EK (2002) Charting time: Timelines as temporal boundary objects. Academy Management Journal 45(5): 956-970. 